\title{
BK channel $\beta 1$ and $\beta 4$ auxiliary subunits exert opposite influences on escalated ethanol drinking in dependent mice
}

\author{
Max Kreifeldt ${ }^{1}$, David Le ${ }^{1+}$, Steven N. Treistman ${ }^{2}$, George F. Koob ${ }^{1}$ and Candice Contet ${ }^{1 *}$ \\ ${ }^{1}$ Committee on the Neurobiology of Addictive Disorders, The Scripps Research Institute, La Jolla, San Diego, CA, USA \\ ${ }^{2}$ Institute of Neurobiology, University of Puerto Rico, San Juan, PR, USA
}

\section{Edited by:}

Melissa A. Herman, The Scripps

Research Institute, USA

Reviewed by:

Robert A. Harris, University of Texas

at Austin, USA

Gilles Martin, University of

Massachusetts Medical School, USA

*Correspondence:

Candice Contet, Committee on the Neurobiology of Addictive Disorder, The Scripps Research Institute, 10550 N Torrey Pines Road SP-102

La Jolla, San Diego, CA 92037, USA e-mail: contet@scripps.edu

${ }^{\dagger}$ Present address:

David Le, Gladstone Institute of Neurological Disease, University of California, San Francisco, San

Francisco, USA
Large conductance calcium-activated potassium (BK) channels play a key role in the control of neuronal activity. Ethanol is a potent activator of BK channel gating, but how this action may impact ethanol drinking still remains poorly understood. Auxiliary $\beta$ subunits are known to modulate ethanol-induced potentiation of BK currents. In the present study, we investigated whether BK $\beta 1$ and $\beta 4$ subunits influence voluntary ethanol consumption using knockout $(\mathrm{KO})$ mice. In a first experiment, mice were first subjected to continuous two-bottle choice (2BC) and were then switched to intermittent 2BC, which progressively increased ethanol intake as previously described in wildtype mice. BK $\beta 1$ or $\beta 4$ subunit deficiency did not affect ethanol self-administration under either schedule of access. In a second experiment, mice were first trained to drink ethanol in a limited-access 2BC paradigm. BK $\beta 1$ or $\beta 4$ deletion did not affect baseline consumption. Weeks of 2BC were then alternated with weeks of chronic intermittent ethanol (CIE) or air inhalation. As expected, a gradual escalation of ethanol drinking was observed in dependent wildtype mice, while intake remained stable in non-dependent wildtype mice. However, CIE exposure only produced a mild augmentation of ethanol consumption in BK $\beta 4 \mathrm{KO}$ mice. Conversely, ethanol drinking increased after fewer CIE cycles in BK $\beta 1 \mathrm{KO}$ mice than in wildtype mice. In conclusion, BK $\beta 1$ or $\beta 4$ did not influence voluntary ethanol drinking in non-dependent mice, regardless of the pattern of access to ethanol. However, deletion of BK $\beta 4$ attenuated, while deletion of BK $\beta 1$ accelerated, the escalation of ethanol drinking during withdrawal from $\mathrm{CIE}$. Our data suggest that BK $\beta 1$ and $\beta 4$ subunits have an opposite influence on the negative reinforcing properties of ethanol withdrawal. Modulating the expression, distribution or interactions of BK channel auxiliary subunits may therefore represent a novel avenue for the treatment of alcoholism.

Keywords: alcohol, knockout mice, two-bottle choice, vapor chambers, dependence

\section{INTRODUCTION}

One of the well-established molecular targets of ethanol is the large conductance calcium-activated (BK) potassium channel. BK channels are widely distributed throughout the body but particularly abundant in the brain, with high levels of expression in the cortex, limbic system, basal ganglia, thalamus and cerebellum (Chang et al., 1997; Sausbier et al., 2006). They play a key role in several aspects of neuronal physiology, including neurotransmitter release, action potential repolarization, firing patterns, and dendritic excitability [see Faber and Sah (2003) for review]. Each native BK channel exists as an assembly of four pore-forming $\alpha$ subunits, potentially associated with four auxiliary $\beta$ subunits. The $\alpha$ subunit is characterized by an exceptionally high conductance for potassium ions $(200-300 \mathrm{pS})$ and is activated both by membrane depolarization and intracellular $\mathrm{Ca}^{2+}$ elevation (Marty, 1981; Butler et al., 1993).

Ethanol potently affects BK channel gating by increasing the time spent in the open state, without altering conductance or ion selectivity (Dopico et al., 1996). The behavioral significance of BK channel potentiation by ethanol is however unclear. In C. elegans, loss-of-function mutations in the gene encoding $\mathrm{BK} \alpha$ subunit led to resistance to ethanol intoxication, while gain-of-function mutations mimicked intoxication (Davies et al., 2003). In contrast, in D. melanogaster, similar manipulations pointed to a role of $\mathrm{BK} \alpha$ subunit in rapid tolerance to the sedative effect of ethanol (Cowmeadow et al., 2005, 2006).

The association of auxiliary $\beta$ subunits modifies the biophysical properties, pharmacology and trafficking of BK $\alpha$ [see Torres et al. (2007); Sun et al. (2012) for reviews]. In particular, $\beta$ subunits modulate the sensitivity of BK currents to ethanol-induced potentiation (Martin et al., 2004; Feinberg-Zadek and Treistman, 2007). Interestingly, deletion of BK $\beta 4$, the most prominent $\beta$ subunit in the brain (Behrens et al., 2000; Brenner et al., 2000), in mice triggered rapid tolerance to the effects of ethanol on BK currents, action potential patterning and locomotion, while increasing limited-access ethanol drinking (Martin et al., 2008). The influence of BK $\beta 1$, which shows low levels of expression in the brain but confers resistance to ethanol-induced activation of BK currents (Martin et al., 2004; Feinberg-Zadek and Treistman, 2007), on the behavioral effects of ethanol remains to be explored. 
In the present study we sought to determine whether BK $\beta 1$ and $\beta 4$ subunits modulate voluntary ethanol consumption. To that end, we tested knockout (KO) mice for the BK $\beta 1$ and $\beta 4$ subunits in several paradigms of two-bottle choice (2BC) drinking.

\section{MATERIALS AND METHODS ANIMALS}

$\mathrm{BK} \beta 1$ and $\beta 4 \mathrm{KO}$ mice were generated by homologous recombination (Brenner et al., 2000, 2005) and fully backcrossed on C57BL/6J background. BK $\beta 1$ and $\beta 4$ wildtype (WT), heterozygous (Het) and KO littermates were bred at The Scripps Research Institute in a temperature $\left(22^{\circ} \mathrm{C}\right)$ and humidity $(50 \%)$ controlled vivarium. Only group-housed males were used in experiments. Mice were at least 10 weeks old when testing started. They were first acclimated for 1 week to reverse light cycle (12-h light/dark cycle, lights on at 10:15 PM). Mice were transferred to individual caging in a dedicated room three days before testing started and remained single-housed for the whole duration of the experiment. Water (acidified) and food (standard rodent chow, Harlan Teklad, Frederick, MD, USA) were available ad libitum at all times. All procedures were carried out in accordance with the National Institutes of Health Guide for the Care and Use of Laboratory Animals and were approved by The Scripps Research Institute Institutional Animal Care and Use Committee.

\section{TWO-BOTTLE CHOICE ETHANOL DRINKING PARADIGMS}

All drinking experiments were conducted in the mouse home cage. Fifty $\mathrm{mL}$ conical tubes fitted with a size 6 rubber stopper and 2.5" stainless steel straight ball tube (Ancare, Bellmore, NY) were used as drinking bottles. Ethanol solutions were prepared with 95\% ethanol (Pharmco-AAPER, Brookfield, CT) and acidified water. Mice were weighed once a week in order to calculate ethanol intake in $\mathrm{g} / \mathrm{kg}$.

\section{Experiment 1: continuous and intermittent access}

$\mathrm{BK} \beta 1$ and $\beta 4 \mathrm{WT}$, Het and KO mice were first offered continuous access to two bottles, one containing ethanol $(20 \% \mathrm{w}: \mathrm{v})$ and one containing water, for two consecutive weeks. Bottles were weighed and their positions inverted every day, Monday through Saturday, at 1:00 PM. Mice were then offered intermittent 24-h access to ethanol for two consecutive weeks. On Tuesdays, Thursdays and Saturdays, the bottle of ethanol was replaced with a bottle of water. On Mondays, Wednesdays and Fridays, the bottle of ethanol was reintroduced, in the position opposite to its last presentation. Bottle weights were recorded every day, Monday through Saturday, at 1:00 PM. This paradigm was adapted from previous publications (Hwa et al., 2011; Melendez, 2011). Under these experimental conditions, C57BL/6J male mice (Jackson Laboratories, Sacramento, CA) offered intermittent access had intoxicating blood alcohol levels (BALs) when tail blood was sampled $1 \mathrm{~h}$ after reintroduction of the ethanol bottle (Supplementary Figure S1). In contrast, BALs were below the intoxication threshold $(80 \mathrm{mg} / \mathrm{dl})$ in mice having continuous access to ethanol, as well as in mice having intermittent access when tail blood was sampled $24 \mathrm{~h}$ after reintroduction of the ethanol bottle (Supplementary Figure S1).

\section{Experiment 2: limited access and dependence induction}

Because of the limited number of available ethanol vapor chambers, this experiment was completed by staggering several cohorts of mice ( 6 cohorts for BK $\beta 1$ and 5 cohorts for BK $\beta 4$ ) over a total duration of 18 months. Importantly, each cohort contained an equivalent number of age-matched $\mathrm{WT}$ and $\mathrm{KO}$ mice and treatment conditions were counterbalanced for both genotypes within each cohort.

BK $\beta 1$ and $\beta 4 \mathrm{WT}$ and KO mice were offered access to two bottles, one containing ethanol $(15 \% \mathrm{v}: \mathrm{v})$ and one containing water, for $2 \mathrm{~h}$ per day from 10:00 AM to 12:00 PM, 5 days a week (Monday through Friday). Bottles were weighed and their positions inverted daily. A standard home cage water bottle was available the rest of the time. Once ethanol intake stabilized (typically after 2 weeks), mice were split into two groups of equivalent baseline, which were later exposed to either chronic intermittent ethanol vapor (CIE) or air inhalation. Weeks of CIE or air exposure were alternated with weeks of $2 \mathrm{BC}$ four times. On a given week of CIE exposure, mice were placed in inhalation chambers and subjected to four cycles of intoxication (ethanol vapor inhalation for $16 \mathrm{~h}$, from 5:00 PM to 9:00 AM, starting Monday afternoon and ending Friday morning) separated by 8 -h periods of withdrawal (air inhalation), and then returned to their home cage for 3 days until 2BC sessions were resumed the following Monday. Weeks of post-vapor (PV) 2BC were conducted in the same way as the baselining (BL) weeks. This paradigm was adapted from previous publications (Becker and Lopez, 2004; Lopez and Becker, 2005).

\section{CHRONIC INTERMITTENT VAPOR INHALATION}

Inhalation chambers (La Jolla Alcohol Research Inc., La Jolla, CA) consisted of standard plastic mouse cages fitted with a Z-shaped wire mesh separation to produce equivalent vapor exposure of two single-housed mice per chamber. Ethanol vapor was created by dripping 95\% ethanol into a 2-L Erlenmeyer vacuum flask kept at $50^{\circ} \mathrm{C}$ on a warming tray. Air was pumped into the flask (HK40L, Hakko, Laguna Hills, CA) and ethanol vapor flew into each sealed chamber at a rate of $3 \mathrm{~L} / \mathrm{min}$. Before each onset of ethanol vapor exposure, mice were injected intraperitoneally with a solution of ethanol $(1.5 \mathrm{~g} / \mathrm{kg})$ and pyrazole $(1 \mathrm{mmol} / \mathrm{kg}$, Sigma, St Louis, MO), an alcohol dehydrogenase inhibitor, to initiate intoxication and maintain constant BALs during the $16 \mathrm{~h}$ of ethanol vapor exposure. Ethanol vapor concentration was adjusted by varying the ethanol dripping rate, so as to yield BALs approximating $200 \mathrm{mg} / \mathrm{dL}$. Each vapor-exposed mouse was typically sampled twice a week, at the end of a 16-h intoxication period. Blood samples were collected from the tail vein with heparinized capillary tubes and centrifuged for $5 \mathrm{~min}$ at $13,000 \mathrm{rpm}$. The supernatant was processed in a GM7 analyzer (Analox Instruments, London, UK). Mice whose average BAL over the whole experiment was below $170 \mathrm{mg} / \mathrm{dL}$ were excluded from data analysis ( 3 out of 39 mice).

\section{DATA ANALYSIS}

Statview software (SAS Institute Inc.) was used for statistical analysis. In Experiment 1, ethanol drinking data were analyzed using a Two-Way repeated-measures (RM) analysis of variance (ANOVA) with daily intake as the dependent variable, time as 
a within-subject factor and genotype as a between-subject factor. Consumptions under continuous (C1 through $\mathrm{C} 15)$ and intermittent (C15 through I7) access were analyzed separately. In Experiment 2, baseline drinking (intake on last day) was analyzed by One-Way ANOVA with genotype as a between-subject factor, while the effect of ethanol vapor exposure was analyzed in each genotype by Two-Way RM-ANOVA with weekly average intake as the dependent variable, time as a within-subject factor and treatment as a between-subject factor. Average intake on a given PV week was also analyzed with unpaired $t$-tests to evaluate differences between genotype and treatment groups. The data are expressed as mean \pm s.e.m. in all graphs.

\section{RESULTS}

BK $\beta 1$ AND $\beta 4$ SUBUNITS DO NOT INFLUENCE CONTINUOUS ETHANOL DRINKING

When given continuous access to ethanol in their home cage, WT mice stabilized their intake $\sim 12-13 \mathrm{~g} / \mathrm{kg} / 24 \mathrm{~h}$ (Figures 1A,B). A Two-Way repeated-measure ANOVA detected an effect of time

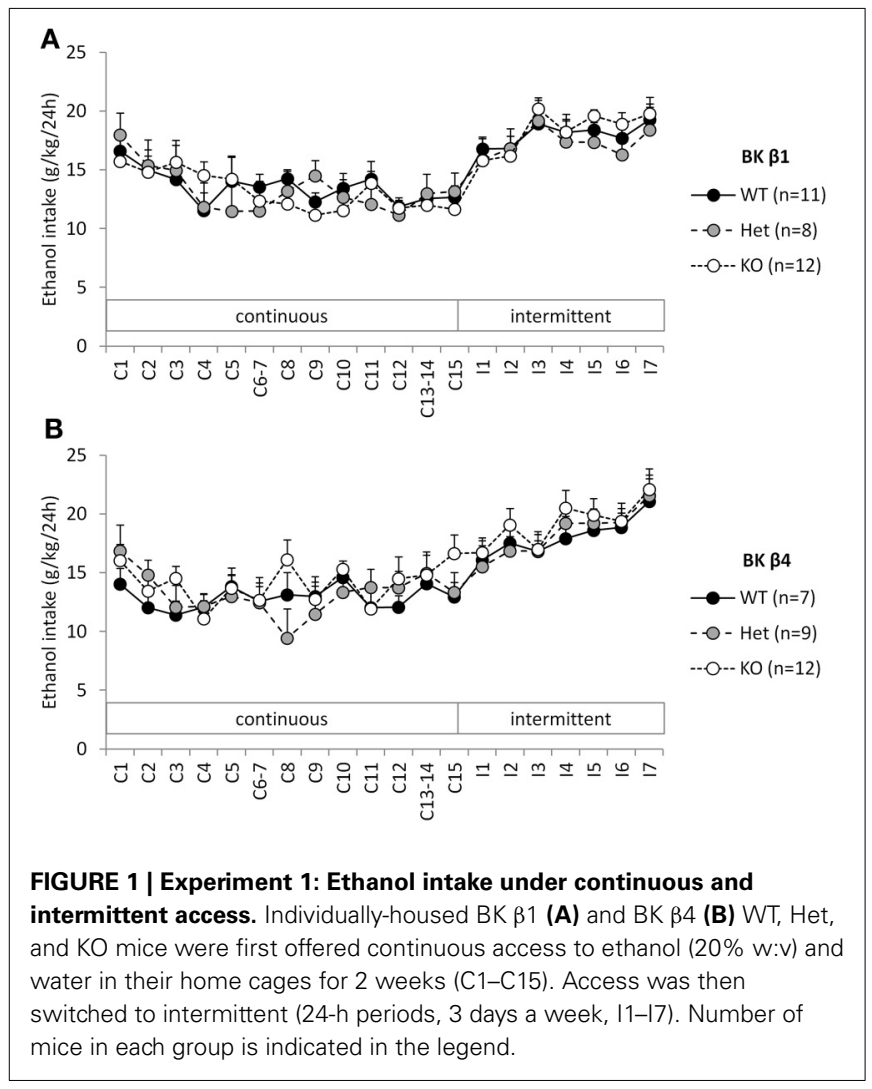

in both strains reflecting the initial intake decline (Table 1). The effect of genotype and the time $\times$ genotype interaction, however, were not significant.

\section{BK $\beta 1$ AND $\beta 4$ SUBUNITS DO NOT INFLUENCE INTERMITTENT ETHANOL DRINKING}

When switched to an intermittent schedule of access to ethanol, WT mice progressively increased their intake up to $\sim 19$ $21 \mathrm{~g} / \mathrm{kg} / 24 \mathrm{~h}$ after 7 sessions (Figures 1A,B). Accordingly, there was a significant effect of time, but there was again no effect of genotype, nor an interaction between time and genotype (Table 1).

\section{BK $\beta 1$ AND $\beta 4$ SUBUNITS DO NOT INFLUENCE LIMITED-ACCESS ETHANOL DRINKING}

When given access to ethanol $2 \mathrm{~h}$ per day at the beginning of the dark cycle, mice stabilized their intake $\sim 2-2.5 \mathrm{~g} / \mathrm{kg}$ (Figures 2A,B, BL week). Deletion of the BK $\beta 1$ or $\beta 4$ subunits again did not affect ethanol drinking under these conditions, as indicated by a One-Way ANOVA $\left(\mathrm{BK} \beta 1: F_{(1,39)}=1.66\right.$, n.s.; BK $\beta 4: F_{(1,35)}=0.66$, n.s.). Likewise, air-exposed $\mathrm{BK} \beta 1$ and $\beta 4 \mathrm{KO}$ mice did not differ from their WT counterparts during any of the subsequent 2BC weeks (Table 3 ).

\section{BK $\beta 1$ DELETION ACCELERATES THE ESCALATION OF ETHANOL DRINKING IN DEPENDENT MICE}

Repeated exposure to cycles of forced ethanol intoxication and withdrawal through the CIE procedure gradually increased voluntary ethanol drinking in BK $\beta 1$ WT mice, while air-exposed counterparts maintained a stable intake throughout the experiment (Figure 2A, PVn weeks). Accordingly, a Two-Way RMANOVA detected a significant interaction between time and treatment (Table 2). CIE-exposed BK $\beta 1 \mathrm{KO}$ mice increased their intake even more robustly, as attested by a stronger interaction between time and treatment, as well as a significant effect of treatment (Table 2). Noticeably, the ethanol consumption of CIEexposed BK $\beta 1 \mathrm{KO}$ mice started rising earlier than for their WT counterparts. Further analysis of intake during PV2 and PV3 detected a significant effect of treatment in $\mathrm{KO}$ mice but not in WT mice (Table 3). In addition, the ethanol intake of CIEexposed BK $\beta 1 \mathrm{KO}$ mice during PV2 was significantly higher than the intake of their WT counterparts (Table 3 ).

\section{BK $\beta 4$ DELETION ATTENUATES THE ESCALATION OF ETHANOL DRINKING IN DEPENDENT MICE}

BK $\beta 4$ WT mice likewise increased their intake following CIE exposure, albeit at a faster pace than BK $\beta 1$ WT mice (Figure 2B, $\mathrm{PVn}$ weeks). Accordingly, the time $\times$ treatment interaction was

Table 1 | Statistical analysis of the effects of time and genotype on ethanol intake in Experiment 1.

\begin{tabular}{|c|c|c|c|c|}
\hline $\begin{array}{l}\text { Experiment } 1 \\
\text { RM-ANOVA }\end{array}$ & \multicolumn{2}{|c|}{ Continuous access } & \multicolumn{2}{|c|}{ Intermittent access } \\
\hline Effect of genotype & $F_{(2,28)}=0.04$, n.s. & $F_{(2,25)}=0.39$, n.s. & $F_{(2,28)}=0.12$, n.s. & $F_{(2,25)}=0.36$, n.s. \\
\hline Time $\times$ genotype interaction & $F_{(24,336)}=1.00$, n.s. & $F_{(24,300)}=1.20$, n.s. & $F_{(14,196)}=0.90$, n.s. & $F_{(14,175)}=0.78$, n.s. \\
\hline
\end{tabular}


strong (Table 2). In contrast, the escalation of ethanol consumption was modest in CIE-exposed $\mathrm{BK} \beta 4 \mathrm{KO}$ mice, as reflected by the lack of time $\times$ treatment interaction in this genotype (Table 2). Further analysis of intake during PV4 confirmed that the effect of treatment was less pronounced in $\mathrm{KO}$ mice than in WT mice, and revealed that CIE-exposed $\mathrm{BK} \beta 4 \mathrm{KO}$ mice

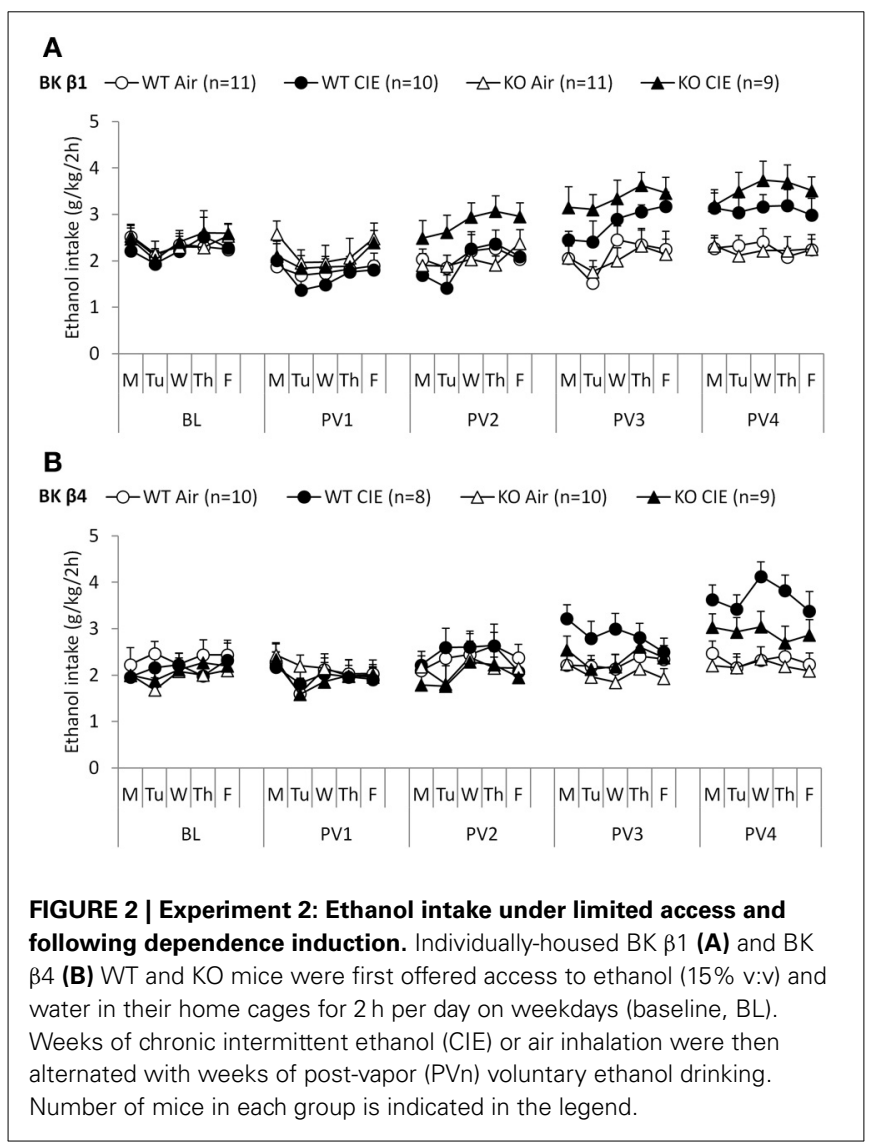

drank significantly less ethanol than their WT counterparts (Table 3).

\section{DISCUSSION}

The present study tested whether BK $\beta 1$ and $\beta 4$ subunits contribute to voluntary ethanol drinking in different paradigms, each emulating a specific consumption pattern and motivational drive. Continuous access to ethanol leads to sporadic bouts of drinking and produces fluctuating BALs with brief peaks of intoxication (as defined by BALs above $80 \mathrm{mg} / \mathrm{dl}$ ), but intake under these conditions may not be entirely driven by the pharmacological effects of ethanol (Dole and Gentry, 1984). Conversely, intermittent and limited access to ethanol lead to binge drinking and produce BALs that positively correlate with intake in C57BL/6J mice (Supplementary Figure S1, Becker and Lopez, 2004; Rhodes et al., 2005; Hwa et al., 2011; Contet et al., 2013). Intake during the binge episode depends on its timing within the light-dark cycle (Rhodes et al., 2005). When occurring few hours into the circadian dark phase (as in the intermittent access model used in the present study), it consistently produces significant intoxication (Supplementary Figure S1, Hwa et al., 2011; Contet et al., 2013). In contrast, if the binge episode occurs at the very beginning of the dark phase (as in the limited access model used in the present study), consumption is lower and BALs are most often not pharmacologically significant (Becker and Lopez, 2004). Dependence induction through CIE exposure however increases the rate of ethanol intake during such limited-access drinking sessions, and accordingly increases blood and brain ethanol concentrations beyond intoxicating levels (Becker and Lopez, 2004; Griffin et al., 2009). Most importantly, voluntary drinking in dependent rodents (i.e., following CIE exposure) is driven by negative reinforcement rather than by the pleasurable effects of ethanol intoxication [see Koob (2003); Gilpin and Koob (2008) for reviews].

Our results indicate that the absence of BK $\beta 1$ or $\beta 4$ subunits doesn't impact voluntary ethanol consumption unless the mice are dependent. In particular, we didn't observe an effect of BK

Table 2 | Statistical analysis of the effects of time and treatment on ethanol intake in each genotype in Experiment 2.

\begin{tabular}{|c|c|c|c|c|}
\hline $\begin{array}{l}\text { Experiment } 2 \\
\text { RM-ANOVA }\end{array}$ & \multicolumn{2}{|c|}{ BK $\beta 1$} & \multicolumn{2}{|c|}{ BK $\beta 4$} \\
\hline Effect of time & $F_{(4,76)}=7.71, p<0.001$ & $F_{(4,72)}=5.14, p<0.01$ & $F_{(4,64)}=8.15, p<0.001$ & $F_{(4,68)}=3.02, p<0.05$ \\
\hline Effect of treatment & $F_{(1,19)}=1.09$, n.s. & $F_{(1,18)}=5.59, p<0.05$ & $F_{(1,16)}=1.88$, n.s. & $F_{(1,17)}=0.41$, n.s. \\
\hline Time $\times$ treatment interaction & $F_{(4,76)}=3.25, p<0.05$ & $F_{(4,72)}=7.43, p<0.001$ & $F_{(4,64)}=6.14, p<0.001$ & $F_{(4,68)}=2.36$, n.s. \\
\hline
\end{tabular}

Table 3 | Statistical analysis of the effects of treatment and genotype on ethanol intake during each $2 \mathrm{BC}$ week in Experiment 2.

\begin{tabular}{|c|c|c|c|c|c|c|c|c|c|c|}
\hline $\begin{array}{l}\text { Experiment } 2 \\
t \text {-test }\end{array}$ & \multicolumn{5}{|c|}{ BK $\beta 1$} & \multicolumn{5}{|c|}{ BK $\beta 4$} \\
\hline KO Air vs. KO CIE & n.s. & n.s. & $p<0.05$ & $p<0.01$ & $p<0.01$ & n.s. & n.s. & n.s. & n.s. & $p<0.05$ \\
\hline WT Air vs. KO Air & n.s. & n.s. & n.s. & n.s. & n.s. & n.s. & n.s. & n.s. & n.s. & n.s. \\
\hline WT CIE vs. KO CIE & n.s. & n.s. & $p<0.05$ & n.s. & n.s. & n.s. & n.s. & n.s. & n.s. & $p<0.05$ \\
\hline
\end{tabular}


$\beta 1$ or $\beta 4$ deletion on binge drinking in either the intermittent or limited-access paradigms. The present observation is at odds with the increased ethanol intake of $\mathrm{BK} \beta 4 \mathrm{KO}$ mice that was previously reported in the "drinking-in-the-dark" model (Martin et al., 2008). In the latter study, mice had access to a single bottle of ethanol during 2-h sessions scheduled $2 \mathrm{~h}$ after lights out. The unavailability of water at a circadian time of high fluid consumption may have resulted in ethanol intake driven by homeostatic needs rather than by hedonic effects, thereby differing from our 2BC paradigms. Another important discrepancy relates to the control mice. Martin et al. bred KO mice in their facility but independently obtained $\mathrm{C} 57 \mathrm{Bl} / 6 \mathrm{~J}$ mice from Jackson Laboratories. In contrast, we used WT and KO littermates, which better controls for raising conditions and other potential artifacts. Altogether, our results support the hypothesis that $\mathrm{BK} \beta 1$ and $\beta 4$ do not modulate binge drinking.

Importantly, dependence-induced escalation of voluntary ethanol consumption was altered in $\mathrm{BK} \beta 1$ and $\beta 4 \mathrm{KO}$ mice. This finding suggests that chronic ethanol intoxication somehow recruits $B K$ auxiliary subunits. It is noteworthy that the absence of BK $\beta 1$ had significant behavioral consequences, although this subunit has been shown to be expressed at very low levels in the brain of naïve mice (Chang et al., 1997; Jiang et al., 1999; Behrens et al., 2000; Brenner et al., 2000). The presence of $\beta 1$ in neurons has however been inferred from the existence of ethanolinsensitive BK channels in nucleus accumbens and hypothalamic neurons, as well as from positive immunostaining (Martin et al., 2004; Wynne et al., 2009). Our data suggest that CIE exposure may induce higher levels of BK $\beta 1$ expression, at least in local brain regions or specific neuronal populations.

Most interestingly, BK $\beta 1$ and $\beta 4$ appear to exert opposite influences on the voluntary ethanol intake of dependent mice, as BK $\beta 1$ deletion accelerated and BK $\beta 4$ attenuated the escalation of drinking in CIE-exposed mice. The divergent phenotypes of $\mathrm{BK} \beta 1$ and $\beta 4 \mathrm{KO}$ mice could result from the differential role of the two subunits in the development of molecular tolerance to ethanol. Since the association of $\beta 1$ has been shown to abolish the sensitivity of BK currents to ethanol-induced potentiation (Martin et al., 2004; Feinberg-Zadek and Treistman, 2007), the putative recruitment of $\mathrm{BK} \beta 1$ would dampen the effect of ethanol on BK channels. Recruitment of BK $\beta 1$ could also reduce ethanol-induced potentiation by regulating the surface expression of $\mathrm{BK} \alpha$ isoforms exhibiting differential ethanol sensitivity (Toro et al., 2006; Kim et al., 2007). The absence of BK $\beta 1$ may prevent such desensitization mechanisms from being engaged in chronically intoxicated $\mathrm{BK} \beta 1 \mathrm{KO}$ mice, which could trigger the onset of cellular adaptations offsetting the prolonged and excessive stimulation of $\mathrm{BK}$ channels by ethanol. These adaptations could facilitate some of the neuroplastic changes underlying the escalation of ethanol intake in dependent animals (Koob, 2003; Gilpin and Koob, 2008), thereby accelerating the increase in voluntary ethanol consumption of CIE-exposed BK $\beta 1 \mathrm{KO}$ mice. Conversely, BK $\beta 4$ has been shown to oppose the development of acute tolerance to the effects of ethanol on BK channel gating, neuronal excitability, and locomotor activity (Martin et al., 2008). The actual mechanism through which $\beta 4$ controls desensitization remains to be elucidated, but it could involve the capacity of $\beta 4$ to modulate the trafficking (Shruti et al., 2012) and phosphorylation status (Petrik et al., 2011; Gilles Martin, personal communication) of BK $\alpha$ in a palmitoylation-dependent manner (Chen et al., 2013). In any case, in the absence of BK $\beta 4$, ethanol-induced potentiation of BK currents is very short-lived, which may attenuate the development of the above-mentioned counteradaptations, thereby limiting the escalation of voluntary ethanol drinking in CIE-exposed BK $\beta 4 \mathrm{KO}$ mice.

Since constitutive KO mice were used in the present study, we cannot exclude that the phenotypes we observed in dependent mice result from a compensatory upregulation of $\beta 1$ in BK $\beta 4$ $\mathrm{KO}$ mice or $\beta 4$ in $\mathrm{BK} \beta 1 \mathrm{KO}$ mice. It should be noted, however, that $\mathrm{BK} \beta 1$ expression in the hippocampus is unaffected by BK $\beta 4$ deletion (Petrik et al., 2011). Another factor that could explain the opposite influence of BK $\beta 1$ and $\beta 4$ on ethanol drinking in dependent mice relates to their differential distributions within brain regions (Chang et al., 1997; Jiang et al., 1999; Behrens et al., 2000; Brenner et al., 2000), neuronal populations (Sugino et al., 2006), and subcellular compartments (Martin et al., 2004; Wynne et al., 2009). Future studies aiming at silencing each subunit in local brain regions of adult animals will help better delineate the role of BK channel auxiliary subunits in the behavioral manifestations of ethanol dependence. Bearing these caveats in mind, our results provide promising evidence that the modulation of BK channel properties can represent a successful strategy to selectively alter the motivational drive of dependent subjects to drink ethanol in excess.

\section{SUPPLEMENTARY MATERIAL}

The Supplementary Material for this article can be found online at: http://www.frontiersin.org/journal/10.3389/fnint.2013. 00105/abstract

Figure S1 | Intermittent access to ethanol drinking produces intoxicating blood alcohol levels. BALs were measured in C57BI/6J mice offered continuous or intermittent access to ethanol (20\% w:v) along with water. Tail blood was sampled $1 \mathrm{~h}(\mathbf{A})$ or $24 \mathrm{~h}$ (B) after the ethanol bottle was reintroduced (intermittent) or repositioned (continuous). Linear regression analysis detected a significant correlation between BAL and ethanol intake when blood was sampled $1 \mathrm{~h}$ after ethanol bottle reintroduction in mice given intermittent access $\left[R^{2}=0.66, F_{(1,5)}=7.61, p=0.05\right.$, dashed line], but not under other circumstances. In the former condition, BALs were above the intoxication threshold $(80 \mathrm{mg} / \mathrm{dL})$ in all mice tested.

\section{REFERENCES}

Becker, H. C., and Lopez, M. F. (2004). Increased ethanol drinking after repeated chronic ethanol exposure and withdrawal experience in C57BL/6 mice. Alcohol. Clin. Exp. Res. 28, 1829-1838. doi: 10.1097/01.ALC.0000149977.95306.3A

Behrens, R., Nolting, A., Reimann, F., Schwarz, M., Waldschutz, R., and Pongs, O. (2000). hKCNMB3 and hKCNMB4, cloning and characterization of two members of the large-conductance calcium-activated potassium channel beta subunit family. FEBS Lett. 474, 99-106. doi: 10.1016/S0014-5793(00)01584-2

Brenner, R., Chen, Q. H., Vilaythong, A., Toney, G. M., Noebels, J. L., and Aldrich, R. W. (2005). BK channel beta4 subunit reduces dentate gyrus excitability and protects against temporal lobe seizures. Nat. Neurosci. 8, 1752-1759. doi: $10.1038 / \mathrm{nn} 1573$

Brenner, R., Perez, G. J., Bonev, A. D., Eckman, D. M., Kosek, J. C., Wiler, S. W., et al. (2000). Vasoregulation by the betal subunit of the calcium-activated potassium channel. Nature 407, 870-876. doi: 10.1038/35038011 
Butler, A., Tsunoda, S., McCobb, D. P., Wei, A., and Salkoff, L. (1993). mSlo, a complex mouse gene encoding "maxi" calcium-activated potassium channels. Science 261, 221-224. doi: 10.1126/science.7687074

Chang, C. P., Dworetzky, S. I., Wang, J., and Goldstein, M. E. (1997). Differential expression of the alpha and beta subunits of the large-conductance calciumactivated potassium channel: implication for channel diversity. Brain Res. Mol. Brain Res. 45, 33-40. doi: 10.1016/S0169-328X(96)00230-6

Chen, L., Bi, D., Tian, L., McClafferty, H., Steeb, F., Ruth, P., et al. (2013). Palmitoylation of the beta4-subunit regulates surface expression of large conductance calcium-activated potassium channel splice variants. J. Biol. Chem. 288, 13136-13144. doi: 10.1074/jbc.M113.461830

Contet, C., Kim, A., Le, D., Iyengar, S. K., Kotzebue, R. W., Yuan, C. J., et al. (2013). mu-Opioid receptors mediate the effects of chronic ethanol binge drinking on the hippocampal neurogenic niche. Addict. Biol. doi: 10.1111/adb.12040. [Epub ahead of print].

Cowmeadow, R. B., Krishnan, H. R., and Atkinson, N. S. (2005). The slowpoke gene is necessary for rapid ethanol tolerance in Drosophila. Alcohol. Clin. Exp. Res. 29, 1777-1786. doi: 10.1097/01.alc.0000183232.56788.62

Cowmeadow, R. B., Krishnan, H. R., Ghezzi, A., Al'Hasan, Y. M., Wang, Y. Z., and Atkinson, N. S. (2006). Ethanol tolerance caused by slowpoke induction in Drosophila. Alcohol. Clin. Exp. Res. 30, 745-753. doi: 10.1111/j.15300277.2006.00087.x

Davies, A. G., Pierce-Shimomura, J. T., Kim, H., Vanhoven, M. K., Thiele, T. R., Bonci, A., et al. (2003). A central role of the BK potassium channel in behavioral responses to ethanol in C. elegans. Cell 115, 655-666. doi: 10.1016/S00928674(03)00979-6

Dole, V. P., and Gentry, R. T. (1984). Toward an analogue of alcoholism in mice: scale factors in the model. Proc. Natl. Acad. Sci. U.S.A. 81, 3543-3546. doi: 10.1073/pnas.81.11.3543

Dopico, A. M., Lemos, J. R., and Treistman, S. N. (1996). Ethanol increases the activity of large conductance, $\mathrm{Ca}(2+)$-activated $\mathrm{K}+$ channels in isolated neurohypophysial terminals. Mol. Pharmacol. 49, 40-48.

Faber, E. S., and Sah, P. (2003). Calcium-activated potassium channels: multiple contributions to neuronal function. Neuroscientist 9, 181-194. doi: $10.1177 / 1073858403009003011$

Feinberg-Zadek, P. L., and Treistman, S. N. (2007). Beta-subunits are important modulators of the acute response to alcohol in human BK channels. Alcohol. Clin. Exp. Res. 31, 737-744. doi: 10.1111/j.1530-0277.2007.00371.x

Gilpin, N. W., and Koob, G. F. (2008). Neurobiology of alcohol dependence: focus on motivational mechanisms. Alcohol Res. Health 31, 185-195.

Griffin, W. C. 3rd., Lopez, M. F., Yanke, A. B., Middaugh, L. D., and Becker, H. C. (2009). Repeated cycles of chronic intermittent ethanol exposure in mice increases voluntary ethanol drinking and ethanol concentrations in the nucleus accumbens. Psychopharmacology (Berl.) 201, 569-580. doi: 10.1007/s00213008-1324-3

Hwa, L. S., Chu, A., Levinson, S. A., Kayyali, T. M., Debold, J. F., and Miczek, K. A. (2011). Persistent escalation of alcohol drinking in C57BL/6J mice with intermittent access to $20 \%$ ethanol. Alcohol. Clin. Exp. Res. 35, 1938-1947. doi: 10.1111/j.1530-0277.2011.01545.x

Jiang, Z., Wallner, M., Meera, P., and Toro, L. (1999). Human and rodent MaxiK channel beta-subunit genes: cloning and characterization. Genomics 55, 57-67. doi: 10.1006/geno.1998.5627

Kim, E. Y., Zou, S., Ridgway, L. D., and Dryer, S. E. (2007). Betal-subunits increase surface expression of a large-conductance $\mathrm{Ca} 2+$-activated $\mathrm{K}+$ channel isoform. J. Neurophysiol. 97, 3508-3516. doi: 10.1152/jn.00009.2007

Koob, G. F. (2003). Alcoholism: allostasis and beyond. Alcohol. Clin. Exp. Res. 27, 232-243. doi: 10.1097/01.ALC.0000057122.36127.C2

Lopez, M. F., and Becker, H. C. (2005). Effect of pattern and number of chronic ethanol exposures on subsequent voluntary ethanol intake in C57BL/6J mice. Psychopharmacology (Berl.) 181, 688-696. doi: 10.1007/s00213-005-0026-3

Martin, G. E., Hendrickson, L. M., Penta, K. L., Friesen, R. M., Pietrzykowski, A. Z., Tapper, A. R., et al. (2008). Identification of a BK channel auxiliary protein controlling molecular and behavioral tolerance to alcohol. Proc. Natl. Acad. Sci. U.S.A. 105, 17543-17548. doi: 10.1073/pnas.0801068105

Martin, G., Puig, S., Pietrzykowski, A., Zadek, P., Emery, P., and Treistman, S. (2004). Somatic localization of a specific large-conductance calciumactivated potassium channel subtype controls compartmentalized ethanol sensitivity in the nucleus accumbens. J. Neurosci. 24, 6563-6572. doi: 10.1523/JNEUROSCI.0684-04.2004

Marty, A. (1981). Ca-dependent K channels with large unitary conductance in chromaffin cell membranes. Nature 291, 497-500. doi: 10.1038/291497a0

Melendez, R. I. (2011). Intermittent (every-other-day) drinking induces rapid escalation of ethanol intake and preference in adolescent and adult C57BL/6J mice. Alcohol. Clin. Exp. Res. 35, 652-658. doi: 10.1111/j.1530-0277. 2010.01383.x

Petrik, D., Wang, B., and Brenner, R. (2011). Modulation by the BK accessory beta4 subunit of phosphorylation-dependent changes in excitability of dentate gyrus granule neurons. Eur. J. Neurosci. 34, 695-704. doi: 10.1111/j.14609568.2011.07799.x

Rhodes, J. S., Best, K., Belknap, J. K., Finn, D. A., and Crabbe, J. C. (2005). Evaluation of a simple model of ethanol drinking to intoxication in C57BL/6J mice. Physiol. Behav. 84, 53-63. doi: 10.1016/j.physbeh.2004.10.007

Sausbier, U., Sausbier, M., Sailer, C. A., Arntz, C., Knaus, H. G., Neuhuber, W., et al. (2006). Ca2+-activated $\mathrm{K}+$ channels of the BK-type in the mouse brain. Histochem. Cell Biol. 125, 725-741. doi: 10.1007/s00418-005-0124-7

Shruti, S., Urban-Ciecko, J., Fitzpatrick, J. A., Brenner, R., Bruchez, M. P., and Barth, A. L. (2012). The brain-specific Beta4 subunit downregulates BK channel cell surface expression. PLOS ONE 7:e33429. doi: 10.1371/journal.pone. 0033429

Sugino, K., Hempel, C. M., Miller, M. N., Hattox, A. M., Shapiro, P., Wu, C., et al. (2006). Molecular taxonomy of major neuronal classes in the adult mouse forebrain. Nat. Neurosci. 9, 99-107. doi: 10.1038/nn1618

Sun, X., Zaydman, M. A., and Cui, J. (2012). Regulation of voltage-activated K(+) channel gating by transmembrane beta subunits. Front. Pharmacol. 3:63. doi: 10.3389/fphar.2012.00063

Toro, B., Cox, N., Wilson, R. J., Garrido-Sanabria, E., Stefani, E., Toro, L., et al. (2006). KCNMB1 regulates surface expression of a voltage and $\mathrm{Ca} 2+$-activated $\mathrm{K}+$ channel via endocytic trafficking signals. Neuroscience 142, 661-669. doi: 10.1016/j.neuroscience.2006.06.061

Torres, Y. P., Morera, F. J., Carvacho, I., and Latorre, R. (2007). A marriage of convenience: beta-subunits and voltage-dependent $\mathrm{K}+$ channels. J. Biol. Chem. 282, 24485-24489. doi: 10.1074/jbc.R700022200

Wynne, P. M., Puig, S. I., Martin, G. E., and Treistman, S. N. (2009). Compartmentalized beta subunit distribution determines characteristics and ethanol sensitivity of somatic, dendritic, and terminal large-conductance calcium-activated potassium channels in the rat central nervous system. J. Pharmacol. Exp. Ther. 329, 978-986. doi: 10.1124/jpet.108.146175

Conflict of Interest Statement: The authors declare that the research was conducted in the absence of any commercial or financial relationships that could be construed as a potential conflict of interest.

Received: 25 November 2013; accepted: 16 December 2013; published online: 30 December 2013.

Citation: Kreifeldt M, Le D, Treistman SN, Koob GF and Contet C (2013) BK channel $\beta 1$ and $\beta 4$ auxiliary subunits exert opposite influences on escalated ethanol drinking in dependent mice. Front. Integr. Neurosci. 7:105. doi: 10.3389/fnint.2013.00105 This article was submitted to the journal Frontiers in Integrative Neuroscience.

Copyright (c) 2013 Kreifeldt, Le, Treistman, Koob and Contet. This is an openaccess article distributed under the terms of the Creative Commons Attribution License (CC BY). The use, distribution or reproduction in other forums is permitted, provided the original author(s) or licensor are credited and that the original publication in this journal is cited, in accordance with accepted academic practice. No use, distribution or reproduction is permitted which does not comply with these terms. 